\title{
Analysis of Network Effect in the Competition of Self- Publishing Market
}

\section{Li Chen ${ }^{1}$ and Wen Tang ${ }^{2}$}

\author{
${ }^{1}$ Fayetteville State University, Broadwell College of Business and Economics, Murchison Road, Fayetteville, NC, \\ USA, Ichen@uncfsu.edu \\ ${ }^{2}$ North Carolina State University, Department of Electrical and Computer Engineering, Oval Drive, Raleigh, NC, USA \\ Wtang6@ncsu.edu
}

Received 17 February 2019; received in revised form 7 September 2019; accepted 1 October 2019

\begin{abstract}
Self-publishing has become a popular e-commerce model. In the current study, we build a duopoly model to examine the impact of the network effect on competition in this emerging market. We investigate four cases depending on two factors: market size and the self-publishing platforms' compatibility strategy. Our results show that self-publishing writers receive higher royalties compared with the scenario of no network effect except in the case of both platforms choosing incompatibility strategy in the standard market. We also find that selfpublishing platforms do not always benefit from the network effect. In the standard market, the platforms will be better off only when they choose incompatibility strategy and the network effect intensity is greater than a certain threshold. In the expanded market, our computational analysis shows that the revenue of the lessknown self-publishing platform increases, but the revenue of the leading platform decreases when both platforms choose compatibility strategy. Our findings also show that both self-publishing platforms prefer incompatibility strategy under a strong network effect in the standard market. Otherwise, they prefer compatibility strategy under a weak network effect. In the expanded market, self-publishing platforms have an incentive to choose incompatibility strategy.
\end{abstract}

Keywords: Self-publishing, Online publishing, Network effect, Compatibility strategy, Duopoly competition 


\section{Introduction}

Recently, self-publishing, mainly in e-book format, has become a popular e-commerce model. Self-publishing refers to the process in which writers directly publish their books through online self-publishing platforms without going through traditional publishers [34]. This new business model has gained popularity because it is less complex and cheaper to publish a book, faster to see the final output, easy to distribute, and most importantly, allows writers to have more control over their books [19].

The emergence and rapid growth of self-publishing have dramatically changed the industry. Waldfogel and Reimers reported that self-publishing has increased 300\% since 2006 [31]. They also found that self-published books started appearing on the list of Amazon best-selling titles in 2011. For example, in the romance fiction on Amazon, almost one-third of the best sellers are self-published books. An industry report from the Nelson book UK showed selfpublished books account for $22 \%$ by volume and $16 \%$ by revenue in the UK book market [6]. According to Bowker, an official International Standard Book Number (ISBN) agency in the United States, self-publishing books increases $40 \%$ in 2018 [5]. To be more specific, the amount of self-publishing books (both print books and e-books) with registered ISBN increases from around 1.2 million in 2017 to more than 1.6 million 2018.

An increasing number of self-publishing platforms have come into the market including Amazon Kindle Direct Publishing (KDP), Smashwords, Lulu, Wattpad, and Draft2Digital. After enrolling in a self-publishing platform, a writer usually has access to the following services: templates or tools to format books, the transformation of manuscripts to e-book formats, cover design, assignments of an International Standard Book Number (ISBN), marketing service, and distribution services. Platforms such as Amazon KDP and Smashwords also help writers publish their books in foreign markets such as Europe, Brazil, India, and Japan.

Different writers choose their self-publishing platform due to their heterogeneous preference. While some writers may prefer the reputation of Amazon, others may prefer the better community design of Smashwords. Prior studies often focus on the difference between self-publishing and traditional publishing [3], [7] and participation of selfpublishing authors [4], [30]. However, extant literature from the perspective of self-publishing providers is sparse, especially on the issue of competition dynamics. In the current study we aim to address this shortcoming by analyzing the competition between self-publishing platforms. In particular, we seek to provide a comprehensive analysis of the impact of the network effect on competition in this market.

Self-publishing services exhibit a positive network effect, which is similar to the effect reflected in digital goods and services such as software [9], [10], online gaming [24], and online music [23]. A positive network effect, also known as network externality, refers to the phenomenon that a consumer's utility increases with the number of consumers who use the same product or service [21]. In the self-publishing market, a platform with a larger number of writers participating is more likely to enhance the performance of its service team. Hence, the platforms are able to better understand self-publishers' needs, develop and timely update service, and incorporate feedback and comments at a faster rate. Reimers and Waldfogel claimed that online platforms such as Amazon have a network effect [27]. Moreover, writers may obtain a social benefit with a larger user base because they can broadly interact with other users. For example, the writers can mutually help promote each other's books, share the reader base, and discuss the usage experience, thus creating a network effect. The larger the user base grows, the stronger the network effect will be. In addition, a large network base of self-publishers helps attract potential indie book lovers as well as independent publishers, which increases the writers' overall benefit. Therefore, a self-publisher's utility is not only determined by the service attributes and royalty but also by the number of writers who participate in the same selfpublishing platform.

Providers of digital services such as self-publishing platforms also need to strategically decide their service compatibility in the presence of network externality [33]. Network size depends on a platforms compatibility strategy. Consequently, different strategies will result in different network-based values for the platforms [9]. For instance, Microsoft's decision to allow the compatibility between Internet Explorer and Open Source Software (OSS) Firefox enhances the richness of consumers' applications, thus creating a larger network base and a network effect. In the self-publishing market, we have witnessed different practice in terms of service compatibility. While Amazon introduced exclusive self-publishing program Amazon KDP Select, platforms such as Smashwords and Draft2Digital do not require such exclusiveness in their service programs. Therefore, we aim to investigate the impact of platforms' compatibility strategies in the self-publishing market in this research.

After taking the network effect and compatibility strategies into consideration, self-publishing platforms might face new challenges in terms of writers' royalty, platform revenue, and service compatibility design. First, the expected return of self-publishing writers' royalty might increase in the presence of the network effect. Second, the network effect may lead to a complicated scenario which might not always benefit self-publishing platforms. Moreover, different strategies of compatibility might lead to different network size and thus result in different network generated values of self-publishing platforms. Naturally, they might want to better understand the competition dynamics in the presence of the network effect. Thus, in this paper, we seek to answer the following research questions: 
1) What impact does the network effect have on the royalties of self-publishing writers?

2) Does the network externality effect always result in benefits to the platforms?

3) Under what conditions will the platforms have the incentive to offer an exclusive or in-exclusive service program in the market?

To address these questions, we employ a duopoly model with a leading self-publishing platform and a less-known self-publishing platform in a horizontal framework. In the presence of the network externality effect, we present our analysis in four different cases based on two factors: market size (standard market versus expanded market) and self-publishing platforms' compatibility strategy (exclusive programs versus in-exclusive programs). Our main findings are as follows. First, the self-publishing writers will receive higher royalties compared with the benchmark scenario in three out of four cases and same royalty in case 2 (standard market with compatibility strategy). Second, self-publishing platforms only benefit from the network effect in certain cases. In the standard market, the platforms will be better off only when they choose an incompatibility strategy (exclusive programs) and the intensity of the network effect exceeds a specific threshold. In the expanded market, the network effect always benefits the lessknown self-publishing platform, but has a mixed effect on the leading self-publishing platform. Third, both platforms have an incentive to choose incompatibility strategy under strong network effect in the standard market. In the expanded market, incompatibility strategy is more desirable for both platforms.

The rest of this paper is organized as follows. In Section 2, we provide a comprehensive review of relevant studies. In Section 3 we develop the duopolistic market structure where self-publishing platforms compete for writers. We use the case of no network effect as the benchmark. Then we analyze the competition in the presence of the network effect between self-publishing platforms under four cases considering both market size and self-publishing platforms' compatibility strategy. In Section 4, we examine the impact of the network effect and the compatibility strategy on the competition dynamics for self-publishing platforms. Section 5 discusses the results of our analysis, answers the research questions and summarizes our contributions. The paper concludes in Section 6 with directions for future research and limitations.

\section{Literature Review}

Our research is closely related to two research streams. The first research stream is related to the literature of selfpublishing. Pioneering research on self-publishing such as Anderson suggested that the lower cost of production and easy distribution will lead to the rapid development of the self-publishing industry [1]. Following research focuses on issues concerning the opportunities and threats of self-publishing [7], the role of independent editors [3], the impact of self-publishing libraries [18], and self-publishing e-textbooks [29]. Baverstock and Steinitz surveyed self-publishing authors and found that most authors choose self-publishing with a purpose to have better control of the content of their books [4]. Thomlison and Belanger suggested that the authors' attitude of e-book self-publishing incorporates normative factors such as symbolic capital in addition to economic factors [30]. Most of the 11 authors they interviewed stated that they think the prestige derived from self-publishing is lower than traditional publishing. Hviid et al. claimed that self-publishing will lead to over-supply of books in the market. Therefore, an intermediary is necessary to solve the problem of asymmetric information about quality for book consumers [19]. Paquet demonstrated that self-publishers can engage online fan networked capital by using word-of-mouth and crowdsourcing [25]. Overall, these studies showed that self-publishing proves to be a viable solution for writers who do not want to go through the laborious process of traditional publishing. However, most of the prior research focuses only on self-publishing development. As more and more firms participate in this emerging market, the issue of competition dynamics needs to be investigated. For example, there is a lack of research exploring how selfpublishing platforms build competitive advantage or providing insights into the impact of key factors such as the network effect and platforms' compatibility strategy.

The second relevant research stream relates to the literature of the network effect in e-commerce. Prior studies have touched upon the impact of the network effect on digital goods and services such as software competition, music recordings [11], online services [24], online music [23], social media [26], and trial-software strategy [35], etc. Recently, Chen and King explored the network effect that e-book lending option has on both monopoly and duopoly markets [8]. They found that in the monopoly setting, the retailer will benefit from the introduction of the e-book lending option when the network effect satisfies certain conditions. In the duopoly setting, introducing the e-book lending option will only benefit the first retailer who offers the program; otherwise, the better-known retailer benefits more. Wu et al. analyzed the impact of the network effect in the market competition of wearable devices [33]. They found that firms obtained smaller profits without considering the network effect. Their model also showed that the network effect will increase the profits of high-quality products, while the profits of low-quality products won't increase unless the network effect is large. Karat et al. (2018) investigated the impact of the network effect in the purchase behavior of game users [20]. Their results revealed that the network effect is more significant in the tail of the market compared with the head of the market. Overall, prior studies in this research stream suggest that consumers' utility changes with the user base in the presence of the network effect, which results in firms' adopting different strategies and behaviors in market competition. 
Our study differs from the past ones in three aspects: First, we investigate the impact of the network effect on competition between self-publishing platforms. This topic has been largely overlooked in prior studies of selfpublishing market. Previous research mainly explores the market from the perspective of the difference between selfpublishing and traditional publishing and the incentives of self-publishing authors. Second, we attempt to provide a comprehensive analysis on the impact of the network effect by analyzing self-publishing platforms' compatibility strategy in both standard market and expanded market and incorporate different levels of network effect intensity. Cheng et al. (2011) also incorporated the market structure in their analysis [9], although they designed a vertical differentiation model and didn't check it in an expanded market setting. Finally, our paper extends the network effect into digital content providers, which is understudied in this literature.

\section{Model}

In this research, we adopt a duopoly model with a horizontal framework for two reasons. First, a duopoly market structure enables us to study the role of the network effect on companies' strategy in competition. Monopoly models do not reflect the competition dynamics in the market. Second, we observe that there are generally two types of selfpublishing platforms. One type of platform is sponsored by a giant online publisher, such as Amazon KDP. Other selfpublishing platforms are of relatively small size such as Smashwords and Wattpad. A duopoly model with one leading platform and one less-known platform naturally reflects the ongoing competition in the self-publishing market. This setting is often used in research on digital goods and services, including the electronic book market [17], cloud computing services [22], and e-book lending market [8]

To capture the heterogeneity of writers' preferences, we model the horizontal differentiation by assuming that writers are uniformly distributed in $[0,1]$ along the axis. Without loss of generality, we assume that platform $A$ is located at zero $(0)$ with higher brand-name recognition and platform B is located at one (1) with lower brand-name recognition. This is inspired by the current online self-publishing market where Amazon KDP program is a leading self-publishing service because of Amazon's dominant position in E-book market and the widespread use of Kindle device [15]. The reserve value $v$ is high enough so the market is fully covered which is a common assumption in differentiation analysis [8], [17], [32]. Figure 1 presents the model, where $\theta$ denotes the indifference point for writers who choose different platforms.

\begin{tabular}{|c|c|c|c|c|c|}
\hline \multirow{2}{*}{ Platform A } & & Self-publish Book & & Self-publish Book & \multirow{2}{*}{ Platform B } \\
\hline & 0 & & $\theta$ & 1 & \\
\hline
\end{tabular}

Figure 1: Standard market of self-publishing

Let $s$ denote the level of brand-name recognition, which represents the overall characteristics of the self-publishing platforms including the quality of service, reputation, marketing support, etc. Karat et al. (2018) suggest that brand name is an important factor for consumers when they choose digital goods such as software [20]. Let $\gamma$ represent the intensity of the network effect, then each writer derives extra utility $(\gamma D)$ under the influence of the network effect, where $D$ is the market share (i.e., the total number of users) of the self-publishing service. Table 1 summarizes the notation used in the model.

Table 1: Summary of notation

\begin{tabular}{|l|l|}
\hline Notation & Interpretation \\
\hline$\theta$ & Location on the horizontal axis \\
\hline$k$ & Intensity of location preference \\
\hline$\gamma$ & Intensity of network effect \\
\hline$v$ & Reserved value \\
\hline$D_{A}, D_{B}$ & Market share of self-publishing service for platform A and platform B \\
\hline$s_{A}, s_{B}$ & Self-publishing service brand-name recognition for platform A and platform B \\
\hline$r_{A}, r_{B}$ & Royalty level of writers in platform A and platform B \\
\hline$\pi_{A}, \pi_{B}$ & Revenue of self-publishing for platform A and platform B \\
\hline
\end{tabular}

In the current study, we first present the benchmark case where there is no network effect. Then we examine the competition in the presence of the network effect in four different cases considering two factors: market size and compatibility strategy. We analyze the competition of self-publishing platforms in two different scenarios: standard market and expanded market. For each scenario, we look at another dimension of competition: self-publishing platforms' compatibility strategy (exclusive service program or in-exclusive service program). We choose these two 
factors because they might significantly influence the competition dynamics in the market. When the market expands with the network impact, platforms' revenue and pricing will change correspondingly. In addition, the compatibility strategy of self-publishing platforms will change the base for the network of writers, leading to different cases of additional utility due to the network effect. Platforms in business practice choose to differ in their compatibility strategy (exclusive service versus in-exclusive service). However, little research has examined the impact of these issues in the competition of self-publishing market. In addition, we allow self-publishing platforms to have different network effect intensity in the scenario of the expanded market.

\subsection{Benchmark Case (no Network Effect)}

In the benchmark case where the market is fully covered, all writers who want to self-publish their books choose to use one of the two self-publishing platforms. In the absence of the network effect, a writer who chooses platform $A$ will derive utility $u_{A}=v+s_{A}-k \theta+r_{A}$, and a writer who chooses platform B will derive utility $u_{B}=v+s_{B}-k(1-$ $\theta)+r_{B}$. We normalize the price of the book to 1 , so we can focus on the royalty. Ultimately, writers have preference on the self-publishing service provider based on their utility. Solving the platforms' revenue function simultaneously, we get the following Lemma:

Lemma 1. When there is no network effect, the royalty offered by platform $A$, and revenue of platform $A$ at equilibrium are as follows: $r_{A}^{*}=1-\frac{3 k+s_{A}-s_{B}}{3}, \pi_{A}^{*}=\frac{\left(3 k+s_{A}-s_{B}\right)^{2}}{18 k}$; The royalty offered by platform $B$, and revenue of platform $B$ at equilibrium are as follows: $r_{B}^{*}=1-\frac{3 k-s_{A}+s_{B}}{3}, \pi_{B}^{*}=\frac{\left(3 k-s_{A}+s_{B}\right)^{2}}{18 k}$. (Please see Appendix $A$ for proof.)

To explore the impact of the network effect in the standard market, we present how writers' utility function will change according to platforms' compatibility strategy, which is a critical aspect in the competition. Different compatibility strategies will bring different network sizes of writers which will lead to different network-generated utilities. If two self-publishing service programs are not exclusive, writers' utility will increase with the total number of users of selfpublishing, regardless of the platform they use. On the other hand, if two self-publishing service programs are exclusive, writers' utility will only increase with the number of users of the same platform. We do not analyze the case of one platform offering exclusive programs and another platform offering in-exclusive programs because at equilibrium both platforms either offer exclusive programs or in-exclusive programs.

\subsection{Standard Market}

As mentioned earlier, our analysis will cover four cases depending on two factors: market size and platforms' compatibility strategy. For the first factor market size, we look at two scenarios: Stardard market and Expended market. In this section, we focus on the standard market with market size normalized to one. We will discuss the scenario in which the market size is greater than one after expansion in section 3.3.

\subsubsection{Case 1: Standard Market, both Platforms Choose Incompatibility Strategy}

In this case, writers who participate in one self-publishing platform will not be allowed to self-publish their books through another platform. For example, Amazon introduced Kindle Direct Publishing Select (KDP Select), which allows writers to earn extra money from KDP Select Global Fund when readers borrow their books from Amazon's ebook subscription programs Kindle Unlimited and Kindle Owners' Lending Library. This program also enables writers to earn up to $70 \%$ royalty in Japan, India, Mexico, and Brazil. However, those writers who enroll in this program would not be able to sell books in other platforms, including the writers' own websites. As a result, the network size will be limited to the users of one particular self-publishing platform. Thus, writers' extra utility based on the network effect using platform $\mathrm{A}$ is $\gamma D_{A}=\gamma \theta$ and writers' extra utility based on the network effect using platform $\mathrm{B}$ is $\gamma D_{B}=$ $\gamma(1-\theta)$. Using the same approach as Lemma 1, we get the following Lemma:

Lemma 2. In the presence of the network effect, under case 1 (standard market with incompatibility strategy), the royalty offered by platform $A$, and revenue of platform $A$ at equilibrium are as follows: $r_{A}^{*}=1-\frac{3 k+s_{A}-s_{B}-3 \gamma}{3}, \pi_{A}^{*}=$ $\frac{\left(3 k+s_{A}-s_{B}-3 \gamma\right)^{2}}{18(k-\gamma)}$; The royalty offered by platform $B$ and revenue of platform $B$ at equilibrium are as follows: $r_{B}^{*}=1-$ $\frac{3 k-s_{A}+s_{B}-3 \gamma}{3}, \pi_{B}^{*}=\frac{\left(3 k-s_{A}+s_{B}-3 \gamma\right)^{2}}{18(k-\gamma)}$. (Please see Appendix B for proof.)

\subsubsection{Case 2: Standard Market, Both Platforms Choose Compatibility Strategy}

Next, we want to discuss the case when both self-publishing platforms choose the compatibility strategy. In other words, the network effect applies to the entire market. When the whole market is fully covered, we are able to see that the impact of the network effect cancels out. Therefore, this case corresponds to the competition in the benchmark case where there is no network effect. Using the same approach as Lemma 1, we get the following Lemma: 
Lemma 3. In the presence of the network effect, under case 2 (standard market with compatibility strategy), the royalty offered by and the revenue of both platform $A$ and platform $B$ at equilibrium are the same as those in the benchmark case. (Please see Appendix $C$ for proof.)

\subsection{Expanded Market}

In the current scenario, we relax two commonly made assumptions in the model. First, prior studies often assume that the market size is fixed as one [8], [9], [13], [16], [17], [32]. However, this assumption may not hold, especially when the self-publishers' increased utility based on the network effect is taken into consideration. For those writers who are not able to publish their books under traditional publishing, they can choose self-publishing by leveraging the network effect, which will result in the expansion of the market size. A similar setting can be found in prior literature [10]. To be more specific, we assume that the market size of the leading platform will increase by $\alpha$ and less-known platform will increase by $\beta$. Figure 2 shows the model for expanded market.

\begin{tabular}{|c|c|c|c|c|}
\hline & Self-publish Book & & & \\
\hline | & 1 & | & & $\beta$ \\
\hline Platform A & 0 & $\theta$ & 1 & Platform B \\
\hline
\end{tabular}

Figure 2: Expanded market of self-publishing

Second, we assume different network effect intensity for the leading platform and the less-known platform whereas the majority of prior research assumes the same network intensity. Since the less-known self-publishing platforms are generally disadvantaged in brand-name recognition, they need to rely on the network effect to compete effectively in the market. Compared with the leading platform Amazon KDP, less-known platforms such as Smashwords and Wattpad provide more user-friendly interface for the community of writers. For example, community members can provide peer reviews and cast votes for the purpose of motivating the writers, especially amateur writers. Self-publishing writers can promote each other's books and share their reader base. These community-based benefits come from the contributions of every other user of the platform. Compared with Amazon KDP, writers using the less-known platform derive more utility from each one of the newly added writers in the network. In the expanded market, we therefore allow the less-known platform to exhibit a stronger network effect intensity than the leading platform $\left(\gamma_{A}<\gamma_{B}\right)$. Under this new scenario, it will be interesting to examine how the impact of the network effect will vary accordingly.

\subsubsection{Case 3: Expanded Market, Both Platforms Choose Incompatibility Strategy}

In this case, a writer who chooses platform A will derive utility $u_{A}=v+s_{A}+\gamma_{A}(\alpha+\theta)-k(\theta+\alpha)+r_{A}$, and a writer who chooses platform $\mathrm{B}$ will derive utility $u_{B}=v+s_{B}+\gamma_{B}(\beta+(1-\theta))-k(1-\theta+\beta)+r_{B}$. Using the same approach for Lemma 1, we get the following Lemma:

Lemma 4. In the presence of the network effect, under case 3 (Expanded market with incompatibility strategy), the royalty offered by platform $A$, and the revenue of platform $A$ at equilibrium are as follows: $r_{A}^{*}=1-$ $\frac{3(1+\alpha+\beta) k+s_{A}-s_{B}-(1+\alpha+\beta) \gamma_{A}-2(1+\alpha+\beta) \gamma_{B}}{3}, \pi_{A}^{*}=\frac{\left((1+\alpha+\beta) \gamma_{A}+2(1+\alpha+\beta) \gamma_{B}-3(1+\alpha+\beta) k-s_{A}+s_{B}\right)^{2}}{18 k-9\left(\gamma_{A}+\gamma_{B}\right)}$; The royalty offered by platform $B$ and revenue of platform $B$ at equilibrium are as follows $r_{B}^{*}=1-\frac{3(1+\alpha+\beta) k-s_{A}+s_{B}-2(1+\alpha+\beta) \gamma_{A}-(1+\alpha+\beta) \gamma_{B}}{3}, \pi_{B}^{*}=$ $\frac{\left(2(1+\alpha+\beta) \gamma_{A}+(1+\alpha+\beta) \gamma_{B}-3(1+\alpha+\beta) k+s_{A}-s_{B}\right)^{2}}{18 k-9\left(\gamma_{A}+\gamma_{B}\right)}$. (Please see Appendix $D$ for proof.)

\subsubsection{Case 4: Expanded Market, Both Platforms Choose Compatibility Strategy}

In this case, a writer who chooses platform $A$ will derive utility $u_{A}=v+s_{A}+\gamma_{A}(1+\alpha+\beta)-k(\theta+\alpha)+r_{A}$, and a writer who chooses platform B will derive utility $u_{B}=v+s_{B}+\gamma_{B}(1+\alpha+\beta)-k(1-\theta+\beta)+r_{B}$. Using the same approach for Lemma 1, we get the following Lemma:

Lemma 5. In the presence of the network effect, under case 4 (Expanded market with compatibility strategy), the royalty offered by platform $A$, and the revenue of platform $A$ at equilibrium are as follows: $r_{A}^{*}=1-$ $\frac{(3-\alpha+\beta) k+s_{A}-s_{B}+(1+\alpha+\beta)\left(\gamma_{A}-\gamma_{B}\right)}{3}, \pi_{A}^{*}=\frac{\left((1+\alpha+\beta)\left(\gamma_{A}-\gamma_{B}\right)-(3-\alpha+\beta) k+s_{A}-s_{B}\right)^{2}}{18 k}$; The royalty offered by platform $B$ and revenue of platform $B$ at equilibrium are as follows: $r_{B}^{*}=1-\frac{(3+\alpha-\beta) k-s_{A}+s_{B}-(1+\alpha+\beta)\left(\gamma_{B}-\gamma_{A}\right)}{3}, \pi_{B}^{*}=\frac{\left((1+\alpha+\beta)\left(\gamma_{B}-\gamma_{A}\right)-(3+\alpha-\beta) k-s_{A}+s_{B}\right)^{2}}{18 k}$. (Please see Appendix E for proof.) 


\section{Results}

In this section, we investigate the impact of the network effect and compatibility strategy on the performance of selfpublishing platforms based on the results of our theoretical model. For the standard market, we compare the equilibrium outcomes in the presence of the network effect (case 1 and case 2) and of the benchmark case without the network effect. For the expanded market, we provide insights by using numerical analysis of results of case 3 and case 4 because the solution is overcomplicated for analytical analysis.

\subsection{Standard Market}

In this subsection, we analyze the market competition including the writers' royalty and the self-publishing platforms' revenue based on the equilibrium outcomes in the standard market (case 1 and case 2) and in the benchmark case. Our key findings are reported in the following propositions.

Proposition 1. Compared with the benchmark case, both the leading self-publishing platform and the less-known selfpublishing platform pay higher royalty to writers in case 1 (standard market with incompatibility strategy). The stronger the network effect is, the larger the increase of the writers' royalty will be. Royalty offered by the less-known platform is higher than that of the leading platform. (Please see the Appendix $C$ for proof.)

The results of this proposition describe the impact of the network effect on royalty. When both self-publishing platforms provide exclusive programs, writers will get higher royalties compared with that of the benchmark case. The stronger the network effect, the higher the increment in royalty. For example, Amazon KDP Select allows participants to get extra revenue from e-book subscription programs such as Kindle Unlimited. In practice, we observed that the less-known platform such as Smashwords offers higher royalties (85\%) to compete with the leading platform, Amazon KDP.

Proposition 2. Define the threshold value $T=k-\frac{\left(s_{A}-s_{B}\right)^{2}}{9 k}$. Compared with the benchmark case, both the leading selfpublishing platform's revenue and the less-known self-publishing platform's revenue increases when $\gamma>T$ in case 1 (standard market with incompatibility strategy). Their revenue will decrease when $\gamma<T$. In addition, the stronger the network effect is, the larger the increase of the platform's revenue will be. Note that the condition of $\gamma<k$ is necessary for the existence of the optimal solution. (Please see the Appendix $C$ for proof.)

Proposition 2 illustrates the two conditions under which the self-publishing platforms will realize more revenue with incompatibility strategy. In the first condition $(\gamma>T)$, the network effect intensity $\gamma$ is required to be greater than $k-$ $\frac{\left(s_{A}-s_{B}\right)^{2}}{9 k}$. When there is a certain gap in the brand-name recognition, the threshold stays low, leading to an ample opportunity to implement the incompatibility strategy. The second condition $(\gamma<k)$ requires that the network effect intensity $\gamma$ is less than the transportation cost $k$ which captures writers' preference for fit of the self-publishing service. In practice, many writers remain committed to their preferred platform and experience high disutility of not choosing that platform. While some writers prefer Amazon KDP because of Amazon's large market size of e-books and wider base of Kindle readers, other writers prefer Smashwords because of its multiple distribution channels and faster payments. Consequently, there is a broad area for $\gamma$ to meet the condition of $\gamma<k$.

Then we further explore the role of the network effect in self-publishing platforms' compatibility strategy. This is an important decision because it will determine whether writers are able to incorporate the network size of the competing platform in their net utility. Comparing the results at equilibrium of Case 1 and Case 2, we find that the platforms' compatibility strategy depends on the strength of the network effect, a key finding summarized in the proposition below:

Proposition 3. Define the threshold value $T=k-\frac{\left(s_{A}-s_{B}\right)^{2}}{9 k}$. In the presence of the network effect in the standard market, self-publishing platforms' compatibility strategy depends on the strength of the network effect. Under a strong network effect $(\gamma>T)$, both self-publishing platforms have more incentives to offer exclusive programs as doing so will increase the revenue; under a weak network effect $(\gamma<T)$, both platforms are more willing to offer in-exclusive programs.

\subsection{Expanded Market}

In this subsection, we analyze the impact of the network effect and compatibility strategy in the expanded market. Closed-form solutions for the equilibrium outcomes such as the optimal revenue under case 3 and case 4 are too complex for analytical comparison. Therefore, we seek managerial insights by using computational analysis. The baseline parameters for the computational analysis are as follows: $s_{A}=1, s_{B}=0.8, k=0.5$. We let $\alpha=0.15, \beta=$ 0.12 so the expansion effect of the market will not be overshadowed by the network effect. We postulate that the less well-known platform has a $10 \%$ advantage in the network effect intensity $\left(\gamma_{B}=1.10 \gamma_{A}\right)$. Thus, changing the value of 
$\gamma_{A}$ will automatically change the value of $\gamma_{B}$. In our analysis, we choose the range of $\gamma_{A}$ as $[0.10,0.15]$. The scale and the ratio of the parameters mentioned above are chosen to represent the relative gap between variables. Figure 3 to Figure 6 below present the results of our analysis.

Observation 1. Compared with the benchmark case, writers benefit from the network effect because both selfpublishing platforms provide higher royalties in the expanded market.

We first check the royalty provided by the self-publishing platforms in the presence of the network effect. As shown in Figure 3(a), the royalty offered by the leading platform (the solid line) always stays above that of the benchmark case (the dashed line). Similar pattern can be observed in Figure 3(b) where the royalty offered by the less-known platform also remains higher than that of the benchmark case.

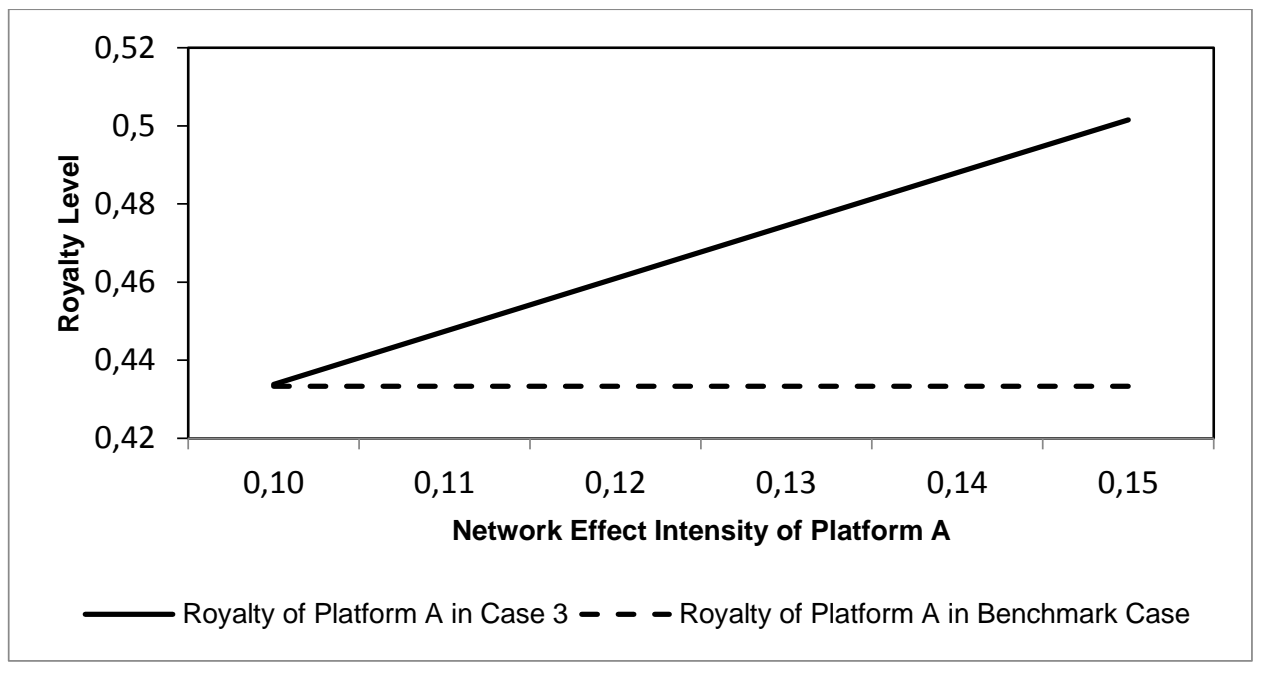

Figures 3 (a): Royalty in platform A with respect to network effect intensity in case 3

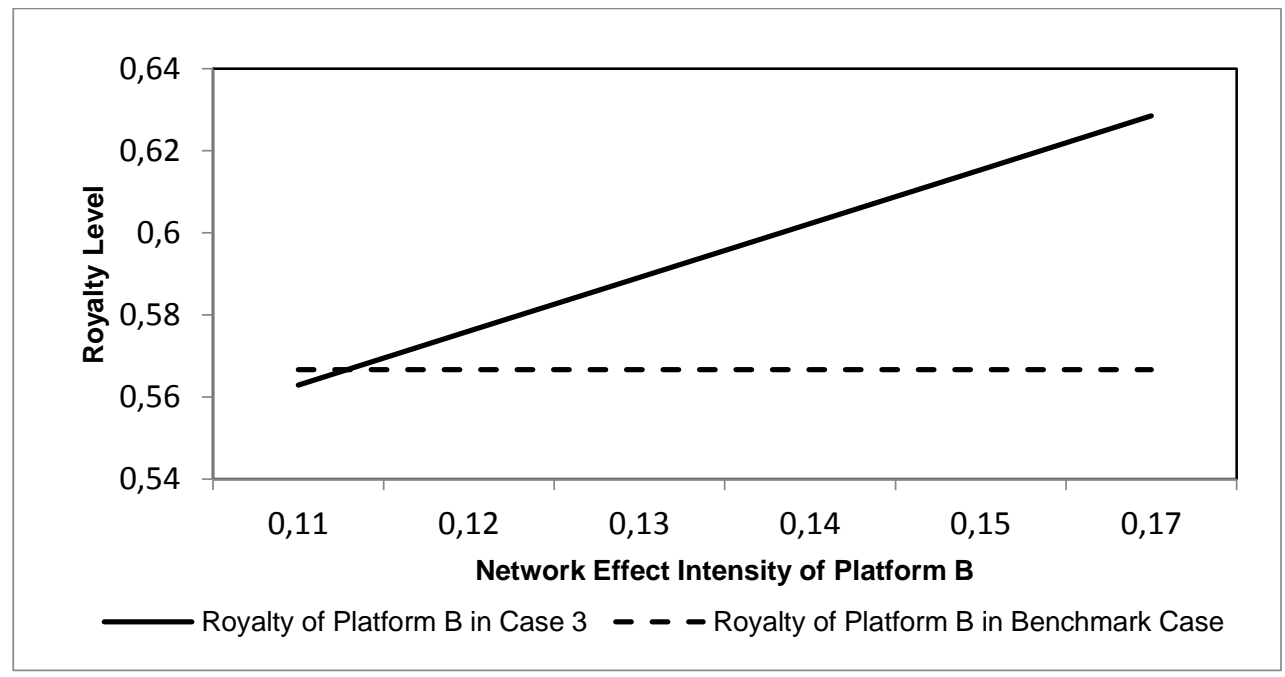

Figures 3 (b): Royalty in platform B with respect to network effect intensity in case 3

Similarly, writers' royalty (the solid line) in case 4 remains higher than that of the benchmark case (the dashed line) in Figure 4(a) and 4(b)). Our findings show that writers will benefit in the presence of the network effect in the expanded market regardless of platforms' compatibility strategy. Combined with the results of the standard market, we find that writers' royalty increases compared with the scenario of no network effect in three out of four cases except in case 2 (standard market with compatibility strategy) in which writers' royalty remains the same. 


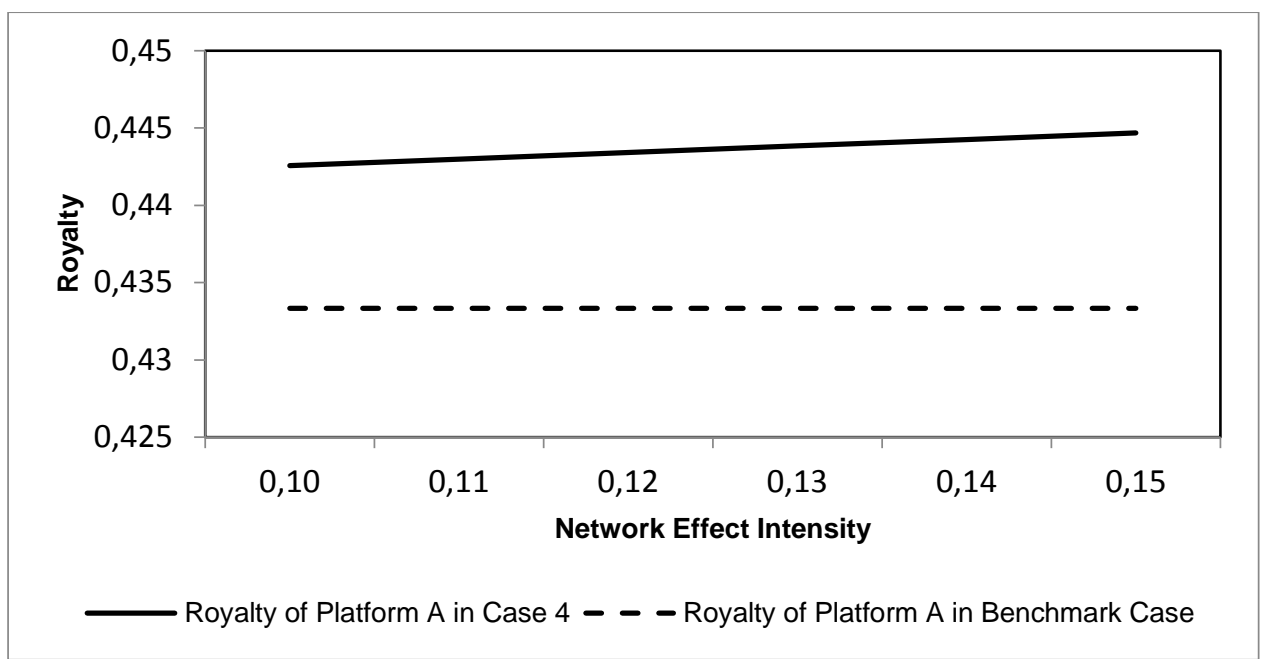

Figures 4 (a): Royalty in platform A with respect to network effect intensity in case 4

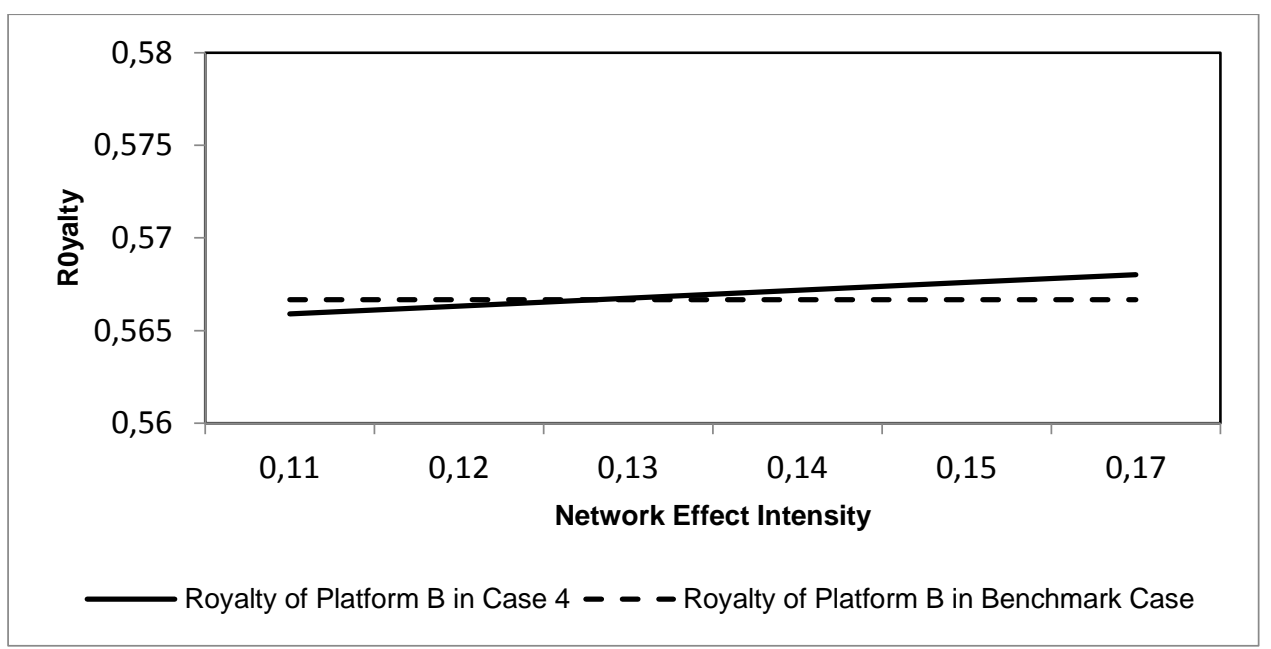

Figures 4 (b): Royalty in platform B with respect to network effect intensity in case 4

Observation 2. In an expanded market, the revenue of the less-known self-publishing platform increases with network effect. However, the impact of network effect is mixed on the leading self-publishing platform. The revenue of the leading self-publishing platform is higher (lower) compared with the benchmark case where both platforms choose incompatibility (compatibility) strategy.

We then analyze self-publishing platforms' revenue in the presence of the network effect. Figure 5(a) and (b) illustrate that revenue of both platforms (the solid line) is higher than that of the benchmark case (the dashed line), suggesting the network effect in general benefits the platforms in case 3 . We also notice that while revenue of the leading platform decreases with the network effect intensity, revenue of the less-known platform increases with the network effect intensity. The stronger the network effect intensity, the greater gap between the revenue in case 3 and that of the benchmark case. 


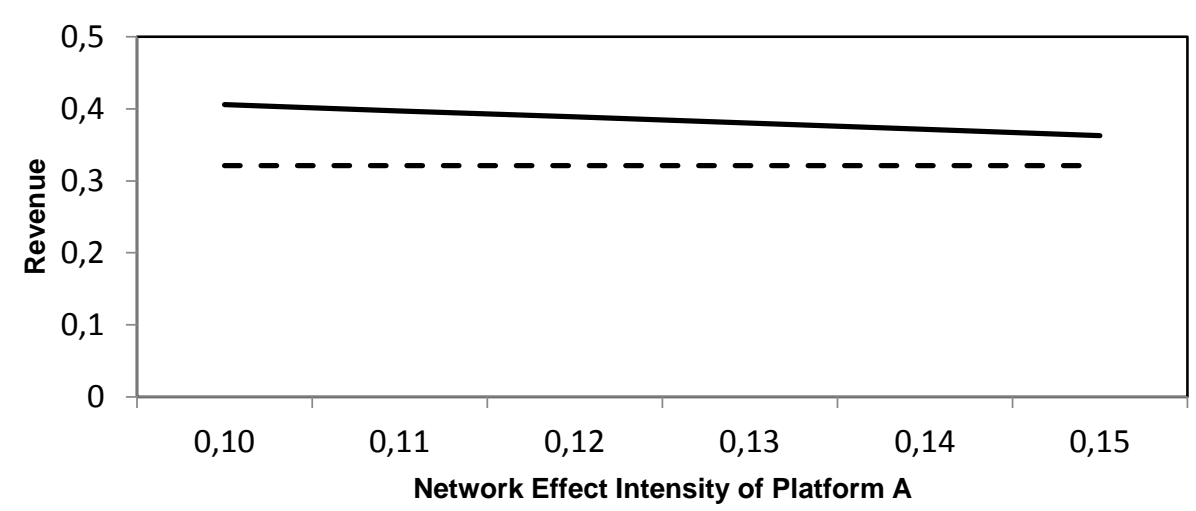

- Revenue of Platform A in Case 3 - - - Revenue of Platform A in Benchmark Case

Figures 5 (a): Revenue in platform A with respect to network effect intensity in case 3

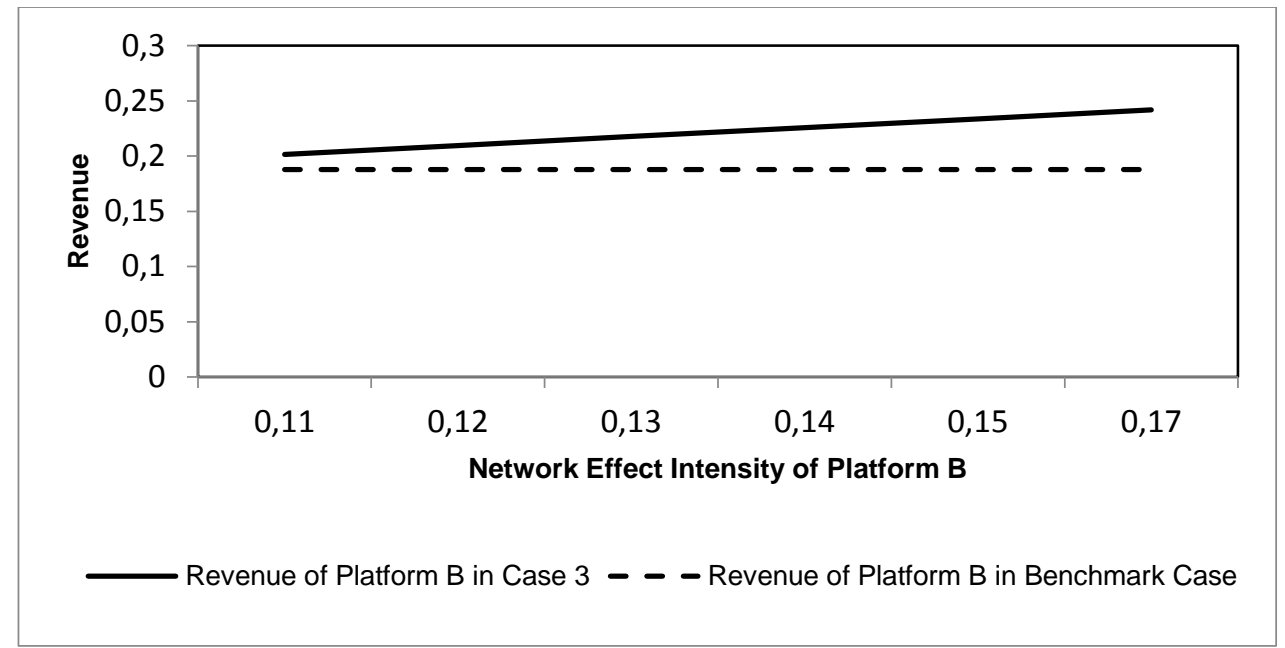

Figures 5 (b): Revenue in platform B with respect to network effect intensity in case 3

For Case 4, we apply computation analysis by using the same parameters. Figure 6(a) shows that different compatibility strategy will change revenue pattern of the leading self-publishing platform. When both platforms provide in-exclusive programs, the leading platform loses revenue compared with the benchmark case. On the other hand, Figure 6 (b) shows that revenue curve of less-known platform remains above that of the benchmark case, thereby indicating that the network effect has a positive impact on the revenue. The stronger the network effect intensity, the greater difference compared with the benchmark case in Figure 6 . The network effect brings a mixed impact on self-publishing platforms when they choose compatibility strategy. 


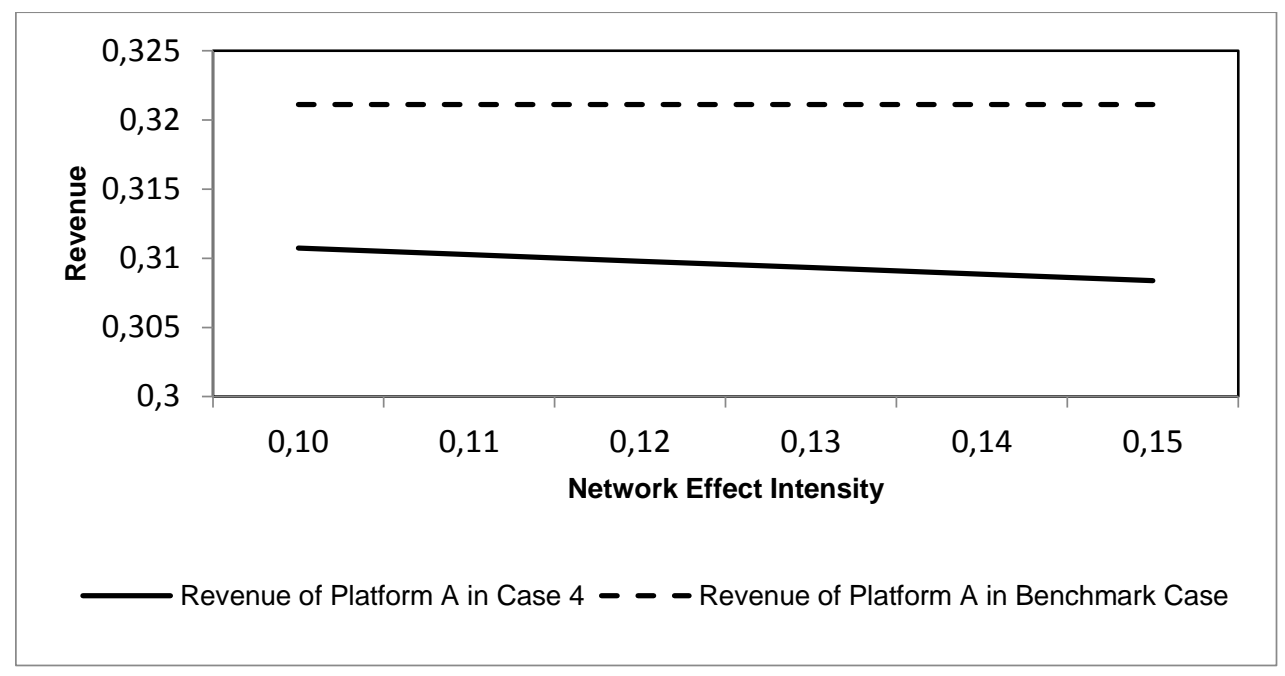

Figures 6 (a): Revenue in platform A with respect to network effect intensity in case 4

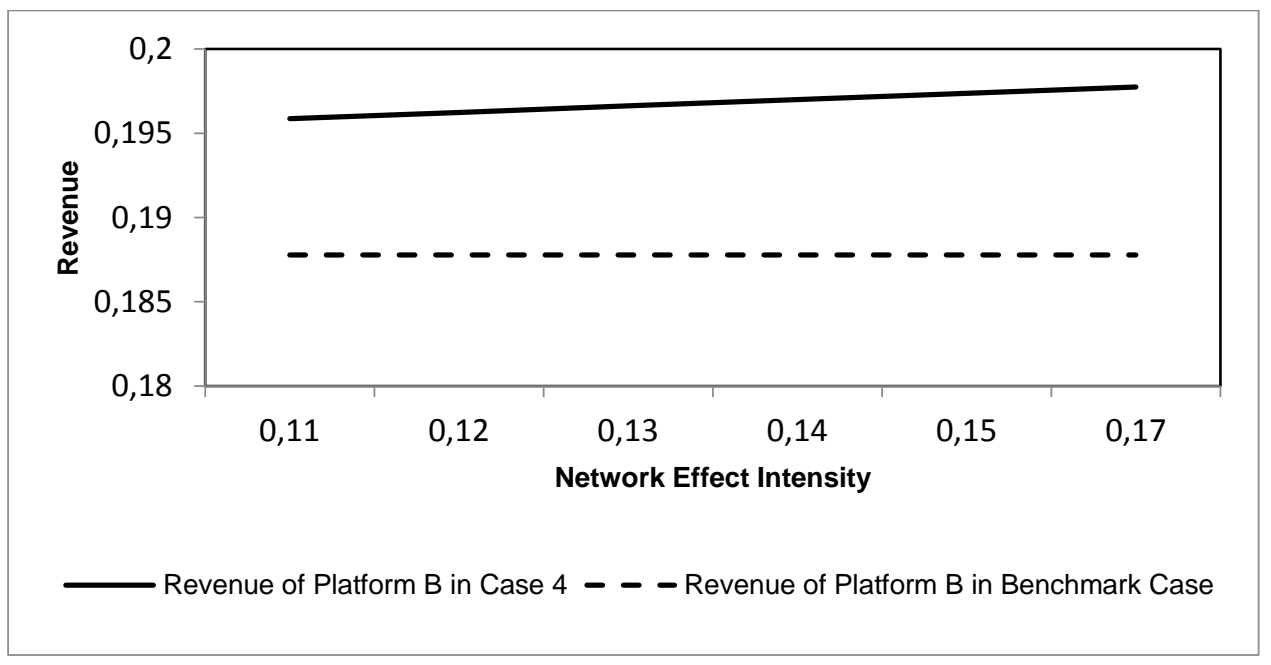

Figures 6 (b): Revenue in platform B with respect to network effect intensity in case 4

Observation 3. In the presence of network effect in the expanded market, incompatibility strategy is preferred by both the leading self-publishing platform and the less known self-publishing platform.

Comparing the results of the computational analysis, we find that the incompatibility strategy is always more desirable for both the leading and the less-known self-publishing platform. For example, Figure 5 and Figure 6 indicate that both platforms are better off in revenue when their programs are not compatible.

\section{Discussion}

Self-publishing has become an important e-commerce model in the era of content digitalization. While more and more self-publishing platforms plunge into this market, research is still lacking as to the competition dynamics between self-publishing service providers. Using a duopoly framework, we investigate the impact of the network effect on the competition dynamics between a leading self-publishing platform and a less-known self-publishing platform. We examine four cases based on market size (standard market versus expanded market) and platforms' compatibility strategy (exclusive programs versus in-exclusive programs). In order to answer the research questions raised in this study, we compute the royalty offered by the platforms and the revenue of the platforms at equilibrium for each case.

For the first research question, our results show that the network effect increases writers' royalty compared with the scenario of no network effect except in case 2 where both platforms choose compatibility strategy in the standard market. This result implies that the presence of the network effect intensifies the battle between self-publishing platforms in terms of attracting writers. The stronger the network effect, the larger increments in the writers' royalty. This finding might explain why more and more writers are interested in the model of self-publishing. Our finding is consistent with prior literature that the network effect might intensify competition among firms [16], [33]. For example, 
Foros and Henson reported a similar finding that lower compatibility level can lead to more intense competition between Internet service providers [14]. The managerial insight here is that both platforms need to prepare a higher return to attract self-publishing writers. For example, Amazon offers rewards for self-publishers [28]. The less-known platform such as Smashwords offers higher royalty to compensate for its lower brand-name recognition. While writers using Amazon KDP receive 35\% royalty for e-books below $\$ 2.99$, and $70 \%$ royalty for e-books between $\$ 2.99$ and $\$ 9.99$, they will receive around $85 \%$ royalty from Smashwords.

Our analysis reflects that the network effect doesn't always benefit the self-publishing platforms, which presents several interesting insights for the second research question. First, in the standard market, when both self-publishing platforms choose the incompatibility strategy, their revenue will increase when the network effect intensity is greater than a specific threshold and less than the intensity of location preference. Prior studies on competition of software [9] and wearable devices [33] also reported the importance of the network effect intensity. Our results suggest that the conditions of generating more revenue are not difficult for self-publishing platforms to satisfy. This finding might explain why Amazon introduced and continuously improved its exclusive self-publishing program Amazon KDP Select. As a result, Amazon's e-book sales increased in 2017 and 2018 partially due to Amazon KDP program [12]. One recommendation is that the self-publishing platforms need to distinguish themselves in their self-publishing service and make writers committed to their programs. Second, when both platforms choose the compatibility strategy in the standard market, the network effect cancels out and their revenue will remain the same. While most prior studies assume that the network effect will change the market competition behavior, our analysis shows that market outcomes might stay the same with the network effect in specific cases. Griva and Vettas reported similar results when two products are fully compatible [16]. Third, in the expanded market, the less-known self-publishing platform always benefits from the network effect. The reason might be that the stronger network effect of less-known platform brings competitive advantage and intensifies the competition. However, the leading self-publishing platform will be worse off when both platforms choose incompatibility strategy. This is fairly different from the literature in that the network effect usually benefits the dominant firms [2], [8], [13]. Overall, we find that the impact of the network effect varies across different cases. The managerial implication is that self-publishing platforms need to apply the appropriate decision tool in the presence of the network effect.

Moreover, our findings show that the network effect plays an important role for answering the third research question. In the standard market, we find that both self-publishing platforms have more incentives to choose incompatibility strategy when network externality effect is strong; otherwise, they are more willing to adopt compatibility strategy. In the expanded market, incompatibility strategy is more desirable to both self-publishing platforms. This can be partly attributed to the fact that the greater network effect arising from the expanded market outweighs the impact of compatibility strategy. One recommendation that can be made from this finding is that both platforms should make their programs less compatible to other platforms' programs in the fast-growing (expanded) self-publishing market. Baake and Boom reported that the high-quality firm prefers incompatibility strategy in a vertical differentiation setting [2]. Farell and Klemperer also reported that the dominant firm wants to use incompatibility strategy [13]. However, our analysis is based on horizontal differentiation setting. Additionally, the self-publishing platforms in our model have similar incentives when choosing their compatibility strategy while prior studies show that dominant or highquality firms have different incentive with other firms.

The current study contributes to the existing research in the following four aspects: first, our study enhances the network effect literature by exploring the impact of the network effect on online service platforms and providing optimal competition strategies. Similar to the network effect of digital goods, the network effect can occur in the selfpublishing scenario, which not only raises the utility of self-publishing writers as the base grows but also attracts potential publishers and book buyers. While most prior studies focus on the features of self-publishing, and the selfpublishing authors, little research has paid attention to competition between self-publishing service providers. Our findings can be generalized to a broader network effect theory of platforms of other digital service such as digital music, online movies and videos, etc. Second, our study enriches the current understanding of the network effect by examining the expanded market with different network effect intensity levels. Our results demonstrate that the network effect presents a different impact in the expanded market compared with that of the standard market. Platforms might consider different strategies for the fast-growing self-publishing market. Incorporating both market size and the compatibility strategy provides self-publishing platforms with much deeper and richer insights in a more dynamic market. Third, we extend the analysis of the network effect into digital content contributors, which is understudied in previous research. In three out of four cases, our analysis shows that the self-publishing writers will benefit in the presence of the network effect. Fourth, current research demonstrates the potential influence of network effect intensity on self-publishing platforms' compatibility strategy. We also find that platforms' incentive differs with market size. Our model provides more concrete decision tools for platforms to determine whether to provide exclusive or in-exclusive programs.

\section{Conclusion}

Using a duopoly model in a horizontal framework, we study online self-publishing platforms' competition dynamics in the presence of the network effect, identify the impact of the network effect on writers' royalty and the revenue of self-publishing platforms, and investigate the incentives of compatibility strategy. We find that the network externality effect in general benefits self-publishing writers except when both platforms choose compatibility strategy in a 
standard market. In addition, our results show that network effect only benefits self-publishing platforms in certain conditions. In the standard market, self-publishing platforms will have higher revenue when network externality effect is large and both platforms choose incompatibility strategy. In the expanded market, network effect increases lessknown platform's revenue but has mixed effect on leading platform's revenue. Moreover, we find that both selfpublishing platforms prefer incompatibility (compatibility) strategy under strong (weak) network effect in the standard market. In the expanded market, self-publishing platforms have an incentive to choose incompatibility strategy.

One limitation of this paper is that we have not considered those writers who directly sell their e-books. With the rapid development of the self-publishing industry, more writers might consider selling books through personal webpages. Another limitation is that we have intentionally chosen to skip writers' switching cost to avoid overcomplexity in the model. In real business practice, writers might not be able to switch between self-publishing platforms freely because of the switching cost. Finally, many assumptions are made for clear presentation of the model and manageability of the calculation. Generalization of our findings can be achieved by adjusting those assumptions.

Our study can be extended for future research in the following aspects: first, in our duopoly framework, we only consider one leading platform and one less-known platform. The self-publishing market can be more complex and future research with an oligopoly model might enhance our understanding of the competition dynamics in the market. Second, future research might study the setting of multi-level competition, such as platforms providing multiple selfpublishing programs with different service options. It will be interesting to investigate what will happen in that setting. Third, future studies might explore the relationship between the added market size and the network effect in the expanded market. Lastly, new studies can examine the impact of the network effect on different types of writers such as professional writers and amateur writers.

\section{Reference}

[1] C. Anderson, The Long Tail: How Endless Choice is Creating Golf to Unlimited Demand. London: Random House, 2006.

[2] P. Baake and A. Boom, Vertical product differentiation, network externalities, and compatibility decisions, International Journal of Industrial Organization, vol. 19, no.1-2, pp. 267-284, 2001.

[3] A. Baverstock, R. Blackburn and M. Iskandarova, How is the role of the independent editor changing in relation to traditional and self-publishing models of publication? Learned Publishing, vol. 28, no. 2, pp. 123-131, 2015

[4] A. Baverstock and J. Steinitz, Who are the self-publishers? Learned Publishing, vol. 26, no. 3, pp. 211-223, 2013.

[5] Bowker. (2019, October) Self-publishing grew 40 percent in 2018, new report reveals. Bowker a ProQuest Affiliate. [Online]. Available: http://www.bowker.com/news/2019/Self-Publishing-Grew-40-Percent-in-2018-NewReport--Reveals.html

[6] L. Campell. (2016, March) Self-published titles 22\% of UK e-book market. The Booksellr. [Online]. Available: https://www.thebookseller.com/news/self-published-titles-22-e-book-market-325152

[7] S. Carolan and C. Evain, Self-publishing: Opportunities and threats in a new age of mass culture, Publishing Research Quarterly, vol. 29, no. 4, pp. 285-300, 2013.

[8] L. Chen and R. King, To lend is to own: A game theoretic analysis of the e-book lending market, International Journal of Electronic Commerce, vol. 21, no. 3, pp.334- 362, Fall 2017.

[9] H.K. Cheng, Y. Liu and Q. Tang, Impact of network between open source and proprietary software, Journal of Management Information Systems, vol. 27, no. 4, pp. 201-230, 2011.

[10] H. K. Cheng and Q. Tang, Free trial or no free trial: Optimal software product design with network effects, European Journal of Operational Research, vol. 205, no. 2, pp. 437-447, 2010.

[11] R. Dewenter, J. Haucap and T. Wenzel, On file sharing with indirect network effect between concerts ticket sales and music recording, Journal of Media Economics, vol. 25, no. 3, pp. 168-178, 2012.

[12] E. Duffer. (2018, July) Amazon e-books sales grow in 2017 and 2018. Forbes. [Online]. Available: https://www.forbes.com/sites/ellenduffer/2018/07/27/amazon-e-book-sales-grow-in-2017-and-2018/\#11d65e69$472 d$

[13] J. Farell and P. Klemperer, Coordination and lock-in: Competition with switching cost and network effect, Handbook of Industrial Organization, vol. 3, 2007, pp. 1967-2072, 2007.

[14] O. Foros and B. Henson, Competition and compatibility among Internet service providers, Information Economics and Policy, vol. 13, no. 4, pp. 411-425, 2001.

[15] R. Gilbert, E-books: A tale of digital disruption,. Journal of Economic Perspective, vol. 29, no. 3, pp. 165-184, 2015.

[16] K. Griva and N. Vettas, Price competition in a differentiated products duopoly under network effect, Information Economics and Policy, vol. 23, no. 1, pp. 85-97, 2011.

[17] L. Hao and M. Fan, An analysis of pricing models in the electronic book market, MIS Quarterly, vol. 38, no. 4, pp. 1017-1032, 2014.

[18] R. P. Holly, Self-Publishing and Collection Development: Opportunities and Challenges for Libraries. West Lafayette, IN, USA, Prudue University Press, 2015.

[19] M. Hviid, S. Sanchez and S. Jacques, From publishers to self-publishing: The disruptive effects of digitalization on the book industry, International Journal of the Economics of Business, vol. 26, no. 3, pp. 355-381, 2019. 
[20] I. Kanat, T. S. Raghu and A. Vinze, Heads or tails? Network effects on game purchase behavior in the long tail market, in Proceedings of the 51st Hawaii International Conference on System Sciences, Hawaii, 2018, pp. 3607-3615.

[21] M. L. Katz and C. Shapiro, Network externality, competition and compatibility, American Economic Review, vol. 75, no. 3, pp. 424-440, 1985.

[22] T. Keskin and N. Taskin, Strategic pricing of horizontally differentiated services with switching costs: A pricing model for cloud computing, International Journal of Electronic Commerce, vol. 19, no. 3, pp. 34-53, 2015.

[23] Y. Lin, Pricing strategies and network effect in the online music industry, The Journal of Human Resources and Adult Learning, vol. 11, no. 1, pp. 24-34, 2015.

[24] God, I M. Pang and H. Etzion, Analyzing pricing strategies for online services with network effect, Information Systems Research, vol. 23, No. 4, pp. 1364-1377, 2012.

[25] L. Paquet, The fan-networked capital of self-published web serials: A comparison of Worm and Nunslinger, Journal of Writing and Writing Courses, vol. 23, no. 1, pp. 1-8, 2019

[26] L. Qiu, Q. Tang and A. Whinston, Two formulas for success in social media: Learning and network effects, Journal of Management Information Systems, vol. 32, no. 4, pp. 78-108, 2015.

[27] I. Reimers and J. Waldfogel, Throw the books at them: Amazon's puzzling long-run pricing strategy, Southern Economic Journal, vol. 83, no. 4, pp. 869-885, 2017.

[28] T. Sanders. (2017, January) Amazon launches $£ 20,000$ prize for self-published ebooks. Telegraph. [Online]. Available: https://www.telegraph.co.uk/books/news/amazon-launches-20000-prize-self-published-ebooks/

[29] L. Schultz, Navigating the minefield of self-publishing E-Textbooks, Information and Systems Education Journal, vol. 15, no. 5, pp. 15-21, 2017.

[30] A. Thomlison and P. C. Belanger, Authors' view of e-book self-publishing: The role of symbolic capital risk, Publication Research Quarterly, vol. 31, pp. 306-316, 2015.

[31] J. Waldfogel and I. Reimers, Storming the gatekeeper: Digital disintermediation in the market of books, Information Economics and Policy, vol. 31, pp. 47-58, 2015.

[32] S. Wattal, R. Telang and T. Mukhopadhyay, Information personalization in a two-dimensional product differentiation model, Journal of Management Information Systems, vol. 26, no. 2, pp. 69-95, 2009.

[33] J. Wu, H. Li, Z. Lin, and H. Zheng, Competition in wearable device market: The effect of network externality and product compatibility, Electronic Commerce Research, vol. 17, no. 3, pp. 335-359, 2017.

[34] Y. Xiong, R. He, G. Li, Z. Xiong, and K. Fernandes, The strategic choices of the goal to obtain publisher, author and retailer in the presence of self-publishing, London, working paper, 2016.

[35] Z. Yi, F. Li and L. Ma, The impact of distribution channels on trial-version provision with a positive network effect, Omega, vol. 85, no. 2, pp. 115-133, 2019. 


\section{Appendix A: Proof of Lemma 1. (Benchmark Case - No Network Effect)}

In this case, writers who choose platform A will derive utility $u_{A}=v+s_{A}-k \theta+r_{A}$, and writers who choose platform B will derive utility $u_{B}=v+s_{B}-k(1-\theta)+r_{B}$;

Letting $u_{A}=u_{B}$, we get the indifference point of writers' location:

$$
\theta=\frac{k+\left(s_{A}-s_{B}\right)+\left(r_{A}-r_{B}\right)}{2 k}
$$

Let $\mathrm{m}_{A}=1-r_{A}$ and $\mathrm{m}_{\mathrm{B}}=1-r_{B}$. Thus, $m_{A} \mathrm{r}$ and $m_{B} r$ epresent the revenue portion that platforms keep. The revenue functions for two competing platforms are as follows:

$$
\begin{gathered}
\pi_{A}=\frac{m_{A}\left(k-m_{A}+m_{B}+s_{A}-s_{B}\right)}{2 k} \\
\pi_{B}=\frac{m_{B}\left(2 k-k+m_{A}-m_{B}-s_{A}+s_{B}\right)}{2 k}
\end{gathered}
$$

We obtain the equilibrium results by solving the First-Order Conditions (FOCs) of revenue over prices on fundamentals for the (i.e., $\frac{\partial \pi_{A}}{\partial m_{A}}=0$ and $\frac{\partial \pi_{B}}{\partial m_{B}}=0$ )

$$
\begin{gathered}
r_{A}^{*}=1-\frac{3 k+s_{A}-s_{B}}{3}, r_{B}^{*}=1-\frac{3 k-s_{A}+s_{B}}{3} ; \theta=\frac{3 k+\left(s_{A}-s_{B}\right)}{6 k} \\
\pi_{A}^{*}=\frac{\left(3 k+s_{A}-s_{B}\right)^{2}}{18 k}, \pi_{B}^{*}=\frac{\left(3 k-s_{A}+s_{B}\right)^{2}}{18 k} .
\end{gathered}
$$




\section{Appendix B: Proof of Lemma 2. (Case 1, Standard Market with Incompatibility Strategy)}

In this case, writers who choose platform A will derive utility $u_{A}=v+s_{A}+\gamma \theta-k \theta+r_{A}$, and writers who choose platform B will derive utility $u_{B}=v+s_{B}+\gamma(1-\theta)-k(1-\theta)+r_{B}$; Letting $u_{A}=u_{B}$, we get the indifference point of writers' location:

$$
\theta=\frac{k+\left(s_{A}-s_{B}\right)+\left(r_{A}-r_{B}\right)-\gamma}{2(k-\gamma)}
$$

Let $\mathrm{m}_{A}=1-r_{A}$ and $\mathrm{m}_{\mathrm{B}}=1-r_{B}$. Thus, the revenue functions for two competing platforms are as follows:

$$
\begin{gathered}
\pi_{A}=\frac{m_{A}\left(k+\left(s_{A}-s_{B}\right)+\left(r_{A}-r_{B}\right)-\gamma\right)}{2(k-\gamma)} \\
\pi_{B}=m_{B}\left(1-\frac{k+\left(s_{A}-s_{B}\right)+\left(r_{A}-r_{B}\right)-\gamma}{2(k-\gamma)}\right)
\end{gathered}
$$

We obtain the equilibrium results by solving the First-Order Conditions (FOCs) of revenue over prices (i.e., $\frac{\partial \pi_{A}}{\partial m_{A}}=0$ and $\left.\frac{\partial \pi_{B}}{\partial m_{B}}=0\right)$

$$
\begin{gathered}
r_{A}^{*}=1-\frac{3 k+s_{A}-s_{B}-3 \gamma}{3}, r_{B}^{*}=1-\frac{3 k-s_{A}+s_{B}-3 \gamma}{3} ; \theta=\frac{3 k+s_{A}-s_{B}-3 \gamma}{6(k-\gamma)} \\
\pi_{A}^{*}=\frac{\left(3 k+s_{A}-s_{B}-3 \gamma\right)^{2}}{18(k-\gamma)}, \pi_{B}^{*}=\frac{\left(3 k-s_{A}+s_{B}-3 \gamma\right)^{2}}{18(k-\gamma)} .
\end{gathered}
$$

To make sure the revenue is positive, the network effect is less than transportation cost $(\gamma<k)$. 


\section{Appendix C: Proof of Lemma 3. (Case 2, Standard Market with Compatibility Strategy)}

In this case, writers who choose platform $\mathrm{A}$ will derive utility $u_{A}=v+s_{A}+\gamma-k \theta+r_{A}$, and writers who choose platform B will derive utility $u_{B}=v+s_{B}+\gamma-k(1-\theta)+r_{B}$

Letting $u_{A}=u_{B}$, we get the indifference point of writers' location:

$$
\theta=\frac{k+\left(s_{A}-s_{B}\right)+\left(r_{A}-r_{B}\right)}{2 k}
$$

We observe that this result is the same as the one of the benchmark case. Therefore, we have the same $m_{A}^{*}, m_{B}^{*}, \pi_{A}^{*}$, $\pi_{B}^{*}$ and $\theta$ as in the benchmark case.

Proof of Proposition 1

We use the superscript 0 to represent the benchmark case, superscript 1 and 2 to represent case 1 and 2 .

$$
\begin{gathered}
\Delta r_{A}=r_{A}^{1, *}-r_{A}^{0, *}=\left(1-m_{A}^{1, *}\right)-\left(1-m_{A}^{0, *}\right)=\frac{3 k+s_{A}-s_{B}}{3}-\frac{3 k+s_{A}-s_{B}-3 \gamma}{3}=\gamma>0 \\
\Delta r_{B}=r_{B}^{1, *}-r_{B}^{0, *}=\left(1-m_{B}^{1, *}\right)-\left(1-m_{B}^{0, *}\right)=\frac{3 k-s_{A}+s_{B}}{3}-\frac{3 k-s_{A}+s_{B}-3 \gamma}{3}=\gamma>0 \\
\frac{\partial \Delta r_{A}}{\partial \gamma}=1>0, \frac{\partial \Delta r_{B}}{\partial \gamma}=1>0
\end{gathered}
$$

Therefore, the writers' royalty increases in both the leading platform and the less-known platform in case 1 . In addition, the royalty level increases with the network intensity. For case 2 , the royalty level remains the same.

Proof of Proposition 2.

We use the same superscripts as the proof of the previous proposition.

$$
\begin{gathered}
\pi_{A}^{1, *}=\frac{\left(3 k+s_{A}-s_{B}-3 \gamma\right)^{2}}{18(k-\gamma)}, \pi_{B}^{1, *}=\frac{\left(3 k-s_{A}+s_{B}-3 \gamma\right)^{2}}{18(k-\gamma)} \\
\Delta \pi_{A}=\pi_{A}^{1, *}-\pi_{A}^{0, *}=\frac{\left(3 k+s_{A}-s_{B}-3 \gamma\right)^{2}}{18(k-\gamma)}-\frac{\left(3 k+s_{A}-s_{B}\right)^{2}}{18 k}=\frac{\gamma\left(9 k \gamma+\left(s_{A}-s_{B}\right)^{2}-9 k^{2}\right)}{18 k(k-\gamma)}
\end{gathered}
$$

When $k-\frac{\left(s_{A}-s_{B}\right)^{2}}{9 k}<\gamma<k, \pi_{A}^{1, *}-\pi_{A}^{0, *}>0$. Otherwise $\pi_{A}^{1, *}-\pi_{A}^{0, *} \leq 0$

$$
\Delta \pi_{B}=\pi_{B}^{1, *}-\pi_{B}^{0, *}=\frac{\left(3 k-s_{A}+s_{B}-3 \gamma\right)^{2}}{18(k-\gamma)}-\frac{\left(3 k-s_{A}+s_{B}\right)^{2}}{18 k}=\frac{\gamma\left(9 k \gamma+\left(s_{A}-s_{B}\right)^{2}-9 k^{2}\right)}{18 k(k-\gamma)}
$$

When $k-\frac{\left(s_{A}-s_{B}\right)^{2}}{9 k}<\gamma<k, \pi_{B}^{1, *}-\pi_{B}^{0, *}>0$. Otherwise $\pi_{B}^{1, *}-\pi_{B}^{0, *} \leq 0$

$$
\frac{\partial \Delta \pi_{A}}{\partial \gamma}>0, \frac{\partial \Delta \pi_{B}}{\partial \gamma}>0
$$




\section{Appendix D: Proof of Lemma 4. (Case 3, Expanded Market with Incompatibility Strategy)}

In this case, writers who choose platform A will derive utility $u_{A}=v+s_{A}+\gamma_{A}(\alpha+\theta)-k(\alpha+\theta)+r_{A}$, and writers who choose platform $B$ will derive utility $u_{B}=v+s_{B}+\gamma_{B}(\beta+(1-\theta))-k(\beta+(1-\theta))+r_{B}$;

Letting $u_{A}=u_{B}$, we get the indifference point of writers' location:

$$
\theta=\frac{k(1-\alpha+\beta)+\left(s_{A}-s_{B}\right)+\left(r_{A}-r_{B}\right)+\alpha \gamma_{A}-(1+\beta) \gamma_{B}}{2 k-\left(\gamma_{A}+\gamma_{B}\right)}
$$

Let $\mathrm{m}_{A}=1-r_{A}$ and $\mathrm{m}_{\mathrm{B}}=1-r_{B}$. Thus, the revenue functions for two competing platforms are as follows:

$$
\begin{gathered}
\pi_{A}=\left(\alpha+\frac{k(1-\alpha+\beta)+\left(s_{A}-s_{B}\right)+\left(m_{B}-m_{A}\right)+\alpha \gamma_{A}-(1+\beta) \gamma_{B}}{2 k-\left(\gamma_{A}+\gamma_{B}\right)}\right) m_{A} \\
\pi_{B}=\left(\beta+1-\frac{k(1-\alpha+\beta)+\left(s_{A}-s_{B}\right)+\left(m_{B}-m_{A}\right)+\alpha \gamma_{A}-(1+\beta) \gamma_{B}}{2 k-\left(\gamma_{A}+\gamma_{B}\right)}\right) m_{B}
\end{gathered}
$$

We obtain the equilibrium results by solving the First-Order Conditions (FOCs) of revenue over prices (i.e., $\frac{\partial \pi_{A}}{\partial m_{A}}=0$ and $\frac{\partial \pi_{B}}{\partial m_{B}}=0$ )

$$
\begin{gathered}
r_{A}^{*}=1-\frac{3(1+\alpha+\beta) k+s_{A}-s_{B}-(1+\alpha+\beta) \gamma_{A}-2(1+\alpha+\beta) \gamma_{B}}{3}, \\
r_{B}^{*}=1-\frac{3(1+\alpha+\beta) k-s_{A}+s_{B}-2(1+\alpha+\beta) \gamma_{A}-(1+\alpha+\beta) \gamma_{B}}{3} ; \\
\theta=\frac{3(1-\alpha+\beta) k+s_{A}-s_{B}-(1-2 \alpha+\beta) \gamma_{A}-(2-\alpha+2 \beta) \gamma_{B}}{3\left(2 k-\left(\gamma_{A}+\gamma_{B}\right)\right)}, \\
\pi_{A}^{*}=\frac{\left((1+\alpha+\beta) \gamma_{A}+2(1+\alpha+\beta) \gamma_{B}-3(1+\alpha+\beta) k-s_{A}+s_{B}\right)^{2}}{18 k-9\left(\gamma_{A}+\gamma_{B}\right)}, \\
\pi_{B}^{*}=\frac{\left(2(1+\alpha+\beta) \gamma_{A}+(1+\alpha+\beta) \gamma_{B}-3(1+\alpha+\beta) k+s_{A}-s_{B}\right)^{2}}{18 k-9\left(\gamma_{A}+\gamma_{B}\right)} .
\end{gathered}
$$




\section{Appendix E: Proof of Lemma 5. (Case 4, Expanded Market with Compatibility Strategy)}

In this case, writers who choose platform $A$ will derive utility $u_{A}=v+s_{A}+\gamma_{A}(1+\alpha+\beta)-k(\alpha+\theta)+r_{A}$, and writers who choose platform $B$ will derive utility $u_{B}=v+s_{B}+\gamma_{B}(1+\alpha+\beta)-k(\beta+(1-\theta))+r_{B}$; Letting $u_{A}=u_{B}$, we get the indifference point of writers' location:

$$
\theta=\frac{k(1-\alpha+\beta)+\left(s_{A}-s_{B}\right)+\left(r_{A}-r_{B}\right)+(1+\alpha+\beta)\left(\gamma_{A}-\gamma_{B}\right)}{2 k}
$$

Let $\mathrm{m}_{A}=1-r_{A}$ and $\mathrm{m}_{\mathrm{B}}=1-r_{B}$. Thus, the revenue functions for two competing platforms are as follows:

$$
\begin{gathered}
\pi_{A}=\left(\alpha+\frac{k(1-\alpha+\beta)+\left(s_{A}-s_{B}\right)+\left(m_{B}-m_{A}\right)+(1+\alpha+\beta)\left(\gamma_{A}-\gamma_{B}\right)}{2 k}\right) m_{A} \\
\pi_{B}=\left(\beta+1-\frac{k(1-\alpha+\beta)+\left(s_{A}-s_{B}\right)+\left(m_{B}-m_{A}\right)+(1+\alpha+\beta)\left(\gamma_{A}-\gamma_{B}\right)}{2 k}\right) m_{B}
\end{gathered}
$$

We obtain the equilibrium results by solving the First-Order Conditions (FOCs) of revenue over prices (i.e., $\frac{\partial \pi_{A}}{\partial m_{A}}=0$ and $\left.\frac{\partial \pi_{B}}{\partial m_{B}}=0\right)$

$$
\begin{array}{r}
r_{A}^{*}=1-\frac{(3-\alpha+\beta) k+s_{A}-s_{B}+(1+\alpha+\beta)\left(\gamma_{A}-\gamma_{B}\right)}{3}, \\
r_{B}^{*}=1-\frac{(3+\alpha-\beta) k-s_{A}+s_{B}-(1+\alpha+\beta)\left(\gamma_{B}-\gamma_{A}\right)}{3} ; \\
\theta=\frac{(3-\alpha+\beta) k+s_{A}-s_{B}+(1+\alpha+\beta)\left(\gamma_{A}-\gamma_{B}\right)}{6 k}, \\
\pi_{A}^{*}=\frac{\left((1+\alpha+\beta)\left(\gamma_{A}-\gamma_{B}\right)+(3-\alpha+\beta) k+s_{A}-s_{B}\right)^{2}}{18 k}, \\
\pi_{B}^{*}=\frac{\left((1+\alpha+\beta)\left(\gamma_{B}-\gamma_{A}\right)+(3+\alpha-\beta) k-s_{A}+s_{B}\right)^{2}}{18 k}
\end{array}
$$

